\title{
Striatal injection of 6-hydroxydopamine induces retrograde degeneration and glial activation in the nigrostriatal pathway ${ }^{1}$
}

\author{
Ricardo Wilson Pinho Rodrigues ${ }^{2}$ \\ Vânia Canterucci Gomide ${ }^{3}$
}

Gerson Chadi ${ }^{4}$

\begin{abstract}
Rodrigues RWP, Gomide VC, Chadi G. Striatal injection of 6-hydroxydopamine induces retrograde degeneration and glial activation in the nigrostriatal pathway. Acta Cir Bras [serial online] 2003 JulAug;18(4). Available from URL: http://www.scielo.br/acb.
\end{abstract}

ABSTRACT - Purpose: The effect of a highly selective 6-hydroxydopamine (6-OHDA)-induced lesion of the nigrostriatal system on the astroglial and microglial activation was analysed in adult Wistar rats after an unilateral striatal injection of the neurotoxin. Methods: Male rats received an unilateral stereotaxical injection of the 6-OHDA in the left side of the neostriatum and were sacrificed 22 days later. Control animals received the injection of the solvent. The rotational behaviour was registered by a rotometer just before the sacrifice. Immunohistochemistry was employed for visualization of the tyrosine hydroxylase $(\mathrm{TH})$ positive dopamine cells, glial fibrillary acidic protein (GFAP) immunolabeled astrocytes and OX42 immunoreactive microglia. Stereological method employing the optical disector was used to estimate the degree of the changes. Results: The striatal injection of the 6-OHDA induced a massive disappearance (32\% of control) of the TH immunoreactive terminals in a defined area within the striatum surrounding the injection site. A disappearance (54\% of control) of dopamine cell bodies was observed in a small region of the ipsilateral pars compacta of the substantia nigra (SNc). The GFAP and OX42immunohistochemistry revealed astroglial and microglial reactions (increases in the number and size of the cells) in the ipsilateral neostriatum and SNc of the 6-OHDA injected rats. Conclusions: The striatal injection of 6-OHDA leads to retrograde degeneration as well as astroglial and microglial activation in the nigrostriatal dopamine pathway. Modulation of activated glial cells may be related to wound repair and to the trophic paracrine response in the lesioned nigrostriatal dopamine system.

KEY WORDS - Astrocyte. Microglia. Immunohistochemistry. Dopamine lesion. Glial activation.

\section{Introduction}

Reactive microglia and astrocytes undergo hiperplasy and hipertrophy following a brain injury ${ }^{1,2,3,4}$. Enlargement of the cell body, increased number and size of astroglial processes and the increased synthesis of glial fibrillary acidic protein (GFAP), an intermediate filament protein of the astroglial cytoskeletum, are indications of the state of astroglial activation following brain damage ${ }^{5}$. Furthermore, microglia also become reactive after central nervous system (CNS) lesion². Furthermore, number and the size of microglial cytoplasm and processes increase few minutes after brain injury ${ }^{6}$. When microglia start to undergo

1. Article from the Laboratory of Neuroregeneration, Department of Anatomy, University of São Paulo (USP), São Paulo, Brazil.

2. Master, Department of Anatomy, University of São Paulo (USP), São Paulo, Brazil.

3. PhD, Department of Anatomy, University of São Paulo (USP), São Paulo, Brazil.

4. Full Professor, Department of Anatomy, University of São Paulo (USP), São Paulo, Brazil. 
phagocytosis, the cells show a round shape and loose their processes. In that state the microglial cells are called ameboid microglia ${ }^{6}$.

In spite of the fact that gliotic scar may represent a physical barrier to axonal regeneration within the $\mathrm{CNS}^{7}$, reactive astrocytes synthetize increased amount of neurotrophic substances ${ }^{8,3,9}$ which are related to the paracrine trophic actions to lesioned neurons ${ }^{10}$.

Many authors have described the mechanisms involved in the cellular paracrine trophic regulation following neuronal lesion ${ }^{11,8}$.

Chemical interaction between activated microglia and astroglia might influence the survival of damaged neurons ${ }^{12,13,7}$. It is known that activated microglia synthetize interleukins that stimulate the activation of astrocytes which in turn produce increased amount of substances with neurotrophic properties ${ }^{7}$.

The degeneration of the nigrostriatal system following a nigral stereotaxical injection of 6hydroxydopamine (6-OHDA) is a well described method to develop parkinsonism in rats ${ }^{14,15}$. However, the analysis of the retrograde degeneration of the nigrostriatal pathway following a striatal unilateral injection of 6-OHDA and the related glial activation are remaining to be detailed investigated.

By means of GFAP and OX42 immunohistochemistry which label astrocyte and microglia, respectively, within the CNS, combined to a computer assisted stereological method, this report has quantified the degree of astroglial and microglial activation following a selective injury of the rat nigrostriatal system promoted by a striatal injection of 6-OHDA. The dopaminergic neurons in the pars compacta of the substantia nigra $(\mathrm{SNc})$ and the terminals in the neostriatum were examined by tyrosine hydroxylase (TH) immunohistochemistry. The apomorphine induced stereotyped rotational behaviour was also employed to evaluate the degree of the nigrostriatal dopamine lesion.

\section{Methods}

Animal: Adult male Wistar rats [body weight (b.w.) 220-250g] from the Institute of Biomedical Sciences (São Paulo, Brazil) were used in the present study. Rats were kept under controlled temperature and humidity conditions with a standardized light and dark cycle (lights on at 7:00 a.m. and off at 7:00 p.m.) with free access to food pellets and tap water.

Neurosurgery and behaviour: The animals received a chloral hydrate anaesthesia (Merck, 0.6mg/100mg b.w.) and were placed in a stereotaxical apparatus (Kopf). The skull was opened with a drill and 6- hydroxydopamine hydrochloride (8?g/4?1, Sigma, U.S.A.), dissolved in $0.9 \%$ saline containing ascorbic acid $(0.2 \mathrm{mg} / \mathrm{ml})$, was unilaterally injected during 15 minutes into the left neostriatum $(n=4)$. The coordinates were $1.2 \mathrm{~mm}$, lateral $2.5 \mathrm{~mm}$, and 4.7 caudal (Figure 1A) according to the atlas of Paxinos and Watson ${ }^{16}$.

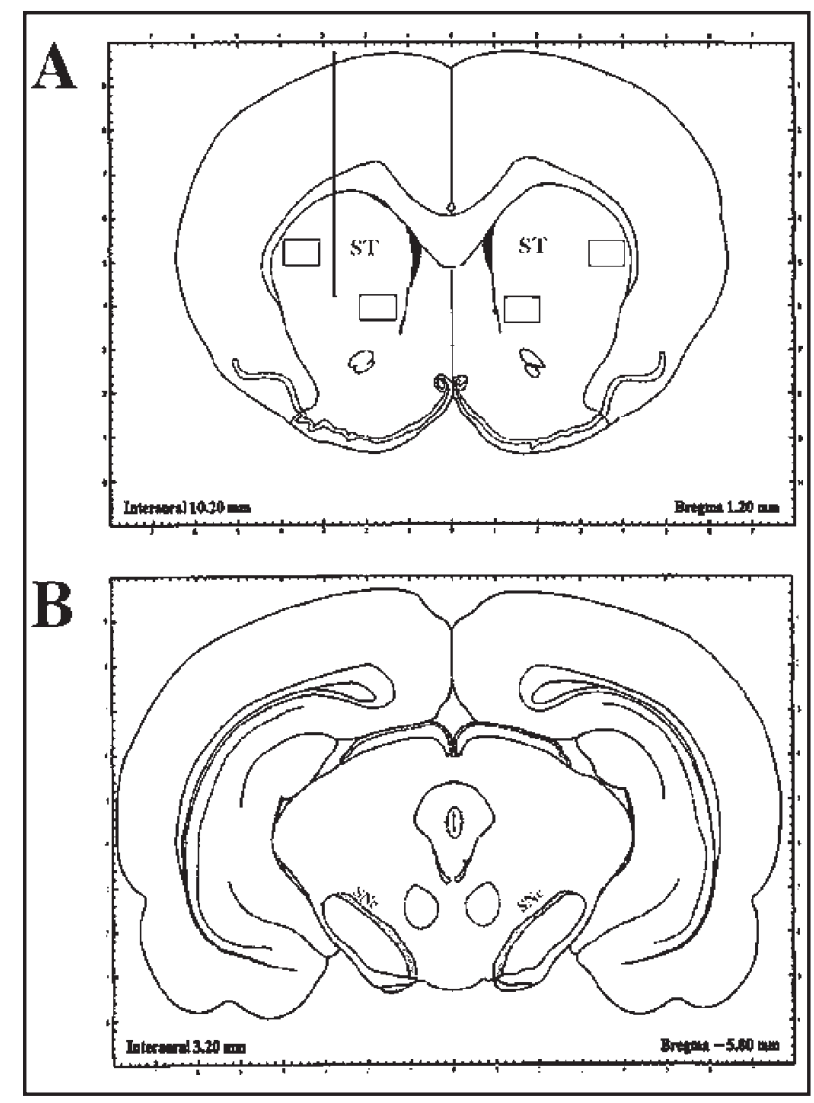

FIGURE 1 - Scheme of coronal sections of the neostriatum (A) and pars compacta of the substantia nigra (B). Bregma $1.20 \mathrm{~mm}$ and $-5.80 \mathrm{~mm}$ (Paxinos and Watson, 1986). The position of the needle used in the 6-hydroxydopamine or solvent injection is illustrated (A). The squares represent the sampled fields for stereological measurements of the TH immunoreactive varicosities and the GFAP and OX42 immunoreactive profiles in the neostriatum (ST), bilaterally (A). In B is shown the sampled fields surrounded in the pars compacta of the substantia nigra $(\mathrm{SNc})$, bilaterally, used for stereological measurements in this region.

The skin was sutured. Control animals received the solvent in the same fashion of the experimental animals. Twenty two days after surgery the rats were placed in the rotometer to evaluate the degree of stereotyped rotation induced by apomorphine following dopamine lesion. 6-OHDA and solvent rats received the nonselective dopamine agonist apomorphine hydrochloride $\left(0.5 \mathrm{mg} / \mathrm{kg}^{-1}\right)$ subcutaneously (s.c.) in the neck and their behaviour was recorded in the rotometer ${ }^{15}$ 
that allows the continuous recording of turns to the left or the rigth (Figure 2). The rotational counts $\left(360^{\circ}\right.$ turns) were recorded at 5 minutes intervals for a total period of 75 minutes. The results were then trasfered to a host computer for analysis. The rotational behaviour of each animal was plotted as a number of $360^{\circ}$ turns $5 \mathrm{~min}^{-1}$ during the entire duration of the recording. The data were plotted and the means \pm s.e.m. were presented. After the recording, the animals were deeply anaesthetized and sacrificed by a transcardiac perfusion with $70 \mathrm{ml}$ isotonic saline at room temperature followed by $350 \mathrm{ml}$ of fixation fluid $\left(4^{\circ} \mathrm{C}\right)$ during 6 minutes. The fixative ${ }^{17}$ consisted of $4 \%$ paraformaldehyde $(\mathrm{w} / \mathrm{v})$ and $0.2 \%$ picric acid $(\mathrm{v} / \mathrm{v})$ in $0.1 \mathrm{M}$ phosphate buffer ( $\mathrm{pH} 6.9$ ). The brains were removed and kept in the fixative solution at $4^{\circ} \mathrm{C}$ for 90 minutes. Following, the brains were rinsed in $20 \%$ sucrose (Merck, Germany) dissolved in $0.1 \mathrm{M}$ phosphate buffered saline, $\mathrm{pH} 7.4$ (PBS) during 48 hours, frozen in dry ice-cooled $\left(-40^{\circ} \mathrm{C}\right)$ isopentane (Sigma) and stored at $-70^{\circ} \mathrm{C}$ until use.

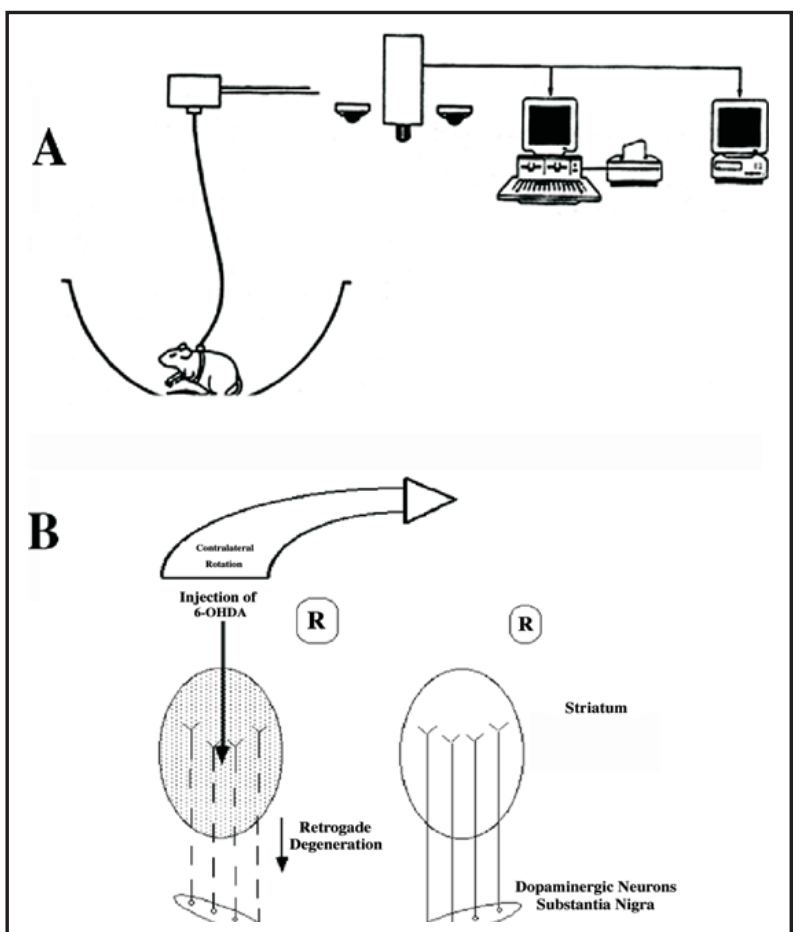

FIGURE 2 - (A) The drawing shows the rotational behaviour analyser system employed to registrate $360^{\circ}$ turns in every 5 minutes after subcutaneous injection of the dopamine agonist apomorphine hydrochloride. The rats were placed in the bowls after apomorphine injecton and the turns were registered in a computer linked system. (B) Scheme showing the unilateral degeneration of the nigrostriatal system following 6hydroxydopamine injection. After degeneration, the dopamine receptors become supersensitive $(\mathrm{R})$ compared to the contralateral side $(\mathrm{R})$. The more intense stimulation in the lesioned side by apomorphine leads the animal to rotate contralaterally.
Immunohistochemistry: Coronal brain adjacent serial $60 ? \mathrm{~m}$ thick sections were obtained in a cryostat (Leica, CM3000, Germany) from rostro-caudal levels of the midbrain $(-4.30 \mathrm{~mm}$ to $-6.30 \mathrm{~mm})$ and forebrain $(+1.60 \mathrm{~mm}$ to $-0.80 \mathrm{~mm})$, respectively, according to the atlas of Paxinos and Watson ${ }^{16}$. The sections were sampled systematically during sectioning. Five or eigth series in a rostro-caudal order including every fifth or eighth section were taken to immunohistochemistry from midbrain or forebrain, respectively. The immunoreactivity was detected using avidin-biotin peroxidase technique ${ }^{18}$. Free-floating sections were washed 2x10 minutes in PBS (0.1M, pH 7.4) at room temperature and incubated with normal goat serum (NGS) $5 \%$ for 30 minutes at room temperature. Following, series of sections were incubated for 48 hours at $4^{\circ} \mathrm{C}$ under shaking with a rabbit polyclonal antiserum to GFAP (Dakopatts, Denmark) diluted $1: 1500$, with a mouse monoclonal antiserum to $\mathrm{TH}$ (Incstar, U.S.A., diluted 1:1000) or with a mouse monoclonal antiserum to OX42 (Harlon, U.K., diluted 1:1000), respectively. The antibodies were diluted in PBS containing $0.5 \%$ Triton X-100 (Sigma) and 1\% bovine serum albumin (Sigma). The sections were washed again in PBS (2x10 minutes) and incubated with biotinylated goat anti-rabbit or horse anti-mouse immunoglobulins (both diluted 1:200, Vector, U.S.A.) for 2 hours. The sections were washed again in PBS and incubated in an avidin-biotin peroxidase complex solution (both diluted 1:100, Vectastain, Vector) for 90 minutes. Visualization of the immunoreactivities was carried out in 3-3-diaminobenzidine tetrahydrocloride (DAB, Sigma) as a chromogen and $\mathrm{H}_{2} \mathrm{O}_{2}(0.05 \%$, v/v, Sigma) for 8-10 minutes.

For standardization of the immunohistochemical procedure we have used a dilution of the primary antibody and a concentration of the DAB far from saturation and an incubation time adjusted so that, the darkest elements in the brain sections were bellow saturation $^{19}$.

The sections were analysed in a AX70 Olympus photomicroscope (U.S.A.). The image were digitalized in a Zeiss microscope (Axioskop 2, Germany).

Stereology. analysis of the estimated number: The optical fractionator ${ }^{20,21}$ was used to sample TH, GFAP and OX42 immunoreactive profiles in sampled fields placed in one section of the SNc and neostriatum (Figures 1A e B). The striatal section showed the epicenter of injection. The GFAP and OX42 as well as the $\mathrm{TH}$ immunoreactive nigral sections were 
counterstained with cresyl violet to allowed interallia visualization of the nucleus which makes the countings more accurate. The TH immunoreactive striatal sections were not counterstained with cresyl violet. TH immunoreactive varicosities, defined as a dilatation of the $\mathrm{TH}$ positive fibers, were counted in the sampled region of the neostriatum. TH dopamine cell bodies counterstained with cresyl violet were counted in the sampled SNc. Astroglial and microglial immunoreactive cells counterstained with cresyl violet were counted in the sampled regions of the neostriatum and SNc.

The stereological analysis was developed using a CAST-system (Computer Assisted Stereological Toolbox). Briefly: an Olympus BX50 microscope (Olympus, Denmark) was interfaced with a computer (IBM 330-P75, U.S.A.) and a colour video camera (JAI 2040, Protec, Japan), both linked to a colour video monitor (G70, IBM). The GRID software package (Interactvision, Silkeborg, Denmark) was used to generate sampling (counting) frames as an overlay image to the microscopic image on the monitor as well as to control the motorized X-Y stage (Lang, Huttenberg, FRG). A microcator (MT12, Heidenhain, FRG) was linked to the microscope to monitor movements in a vertical $(\mathrm{Z})$ direction. The border of the region to be quantified was outlined using a $4 \mathrm{x}$ objective (Figure $1 \mathrm{~A}, \mathrm{~B})$. The step rates were entered (70-150 $\mu \mathrm{m}$ depending on the immunoreactivity analysed), after which the program created series of uniformly sampled fields of vision throughout the entire delimitated regions. For counting the profiles, a 100x oil-immersion objective with the numerical aperture 1.4 was used. The counting frames (with a known area, $\mathrm{a}_{\text {frame }}$ ) were created by the GRID software. The sampling volume (disector) in the Z-axis extended 3-20 $\mu \mathrm{m}$ deep (height of the disector) after excluding the parts of the section close to the slide and coverslip $(3-5 \mu \mathrm{m})$. Also the total thickness of the section was measured in each sampled field. The estimated number of immunoreactive profiles inside the sampled field was calculated according to the formula: $\mathrm{N}=\mathrm{Q}^{-} \cdot f_{1} \cdot f_{2}$. The numbers of the ipsilateral and contralateral sides of the 6-OHDA striatal injection were presented. The numbers of ipsilateral and contralateral striatum represent the mean of the estimated number in two sampled fields of each striatal side (Figure 1A).

Statistical analysis: Statistical analysis was performed according to the non-parametric two-tailed Mann-Whitney U-test ${ }^{22}$. The sham operated and 6OHDA treated groups were compared.

\section{Results}

Rotational behaviour: Apomorphine induced an increased number of contralateral rotation in the unilateral 6-OHDA striatal injected rats 22 days after the lesion (Figure 3). Contralateral turning was not seen in the solvent striatal injected animals following apomorphine stimulation (Figure 3). Furthermore, ipsilateral rotation was not found either in the 6-OHDA or solvent striatal injected rats after apomorphine injection by 22 days after surgery (Figure 3 ).

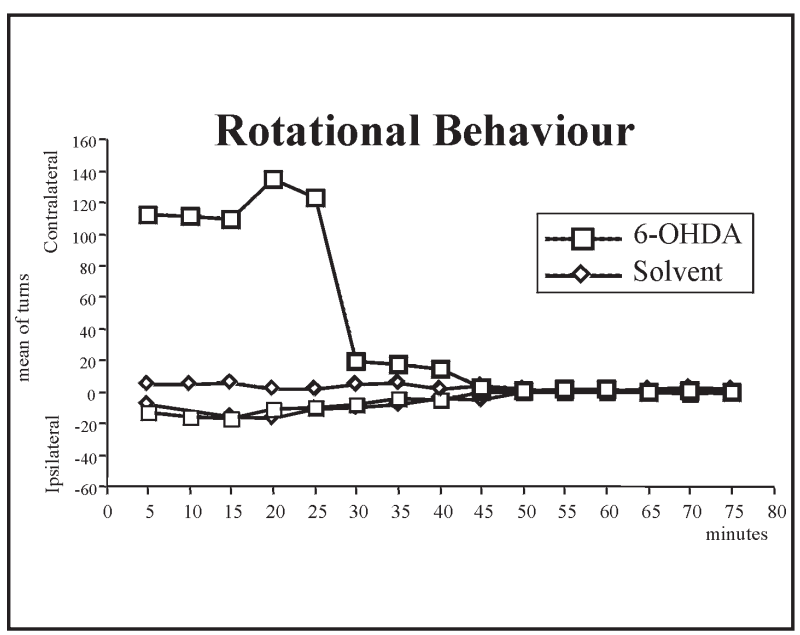

FIGURE 3 - Effects of the unilateral striatal injection of 6hydroxydopamine in a dose of $8 \mathrm{mg} / 4 \mathrm{ml}$ (?) or solvent (?) on the mean of contralateral (positive numbers) and ipsilateral (negative numbers) turns after a subcutaneuos injection of the dopamine agonist apomorphine hydrochloride $\left(0.5 \mathrm{mg} / \mathrm{kg}^{-1}\right) 22$ days after injury. The numbers represent the mean of turns every 5 minutes during 75 minutes. $n=4-3$.

TH immunoreactivity: $\mathrm{TH}$ immunoreactive terminals were found to be disappeared in a defined area within the ipsilateral neostriatum surrounding the site of the 6-OHDA injection 22 days after the surgery (Figures 4A e B). A slight disappearance of the TH immunoreactive fibers was seen in the ipsilateral neostriatum of the solvent injected rats only close to the needle track (not shown). Furthermore, a disappearance of dopamine cell bodies was observed in a defined region of the ipsilateral SNc of the 6-OHDA lesioned rats (Figure 4D). No changes in the TH immunoreactivity were seen within the contralateral neostriatum and SNc of the 6-OHDA injected rats. Also, no disappearance of dopamine cells was found in the $\mathrm{SNc}$ of the solvent treated rats (Figure 4C). 

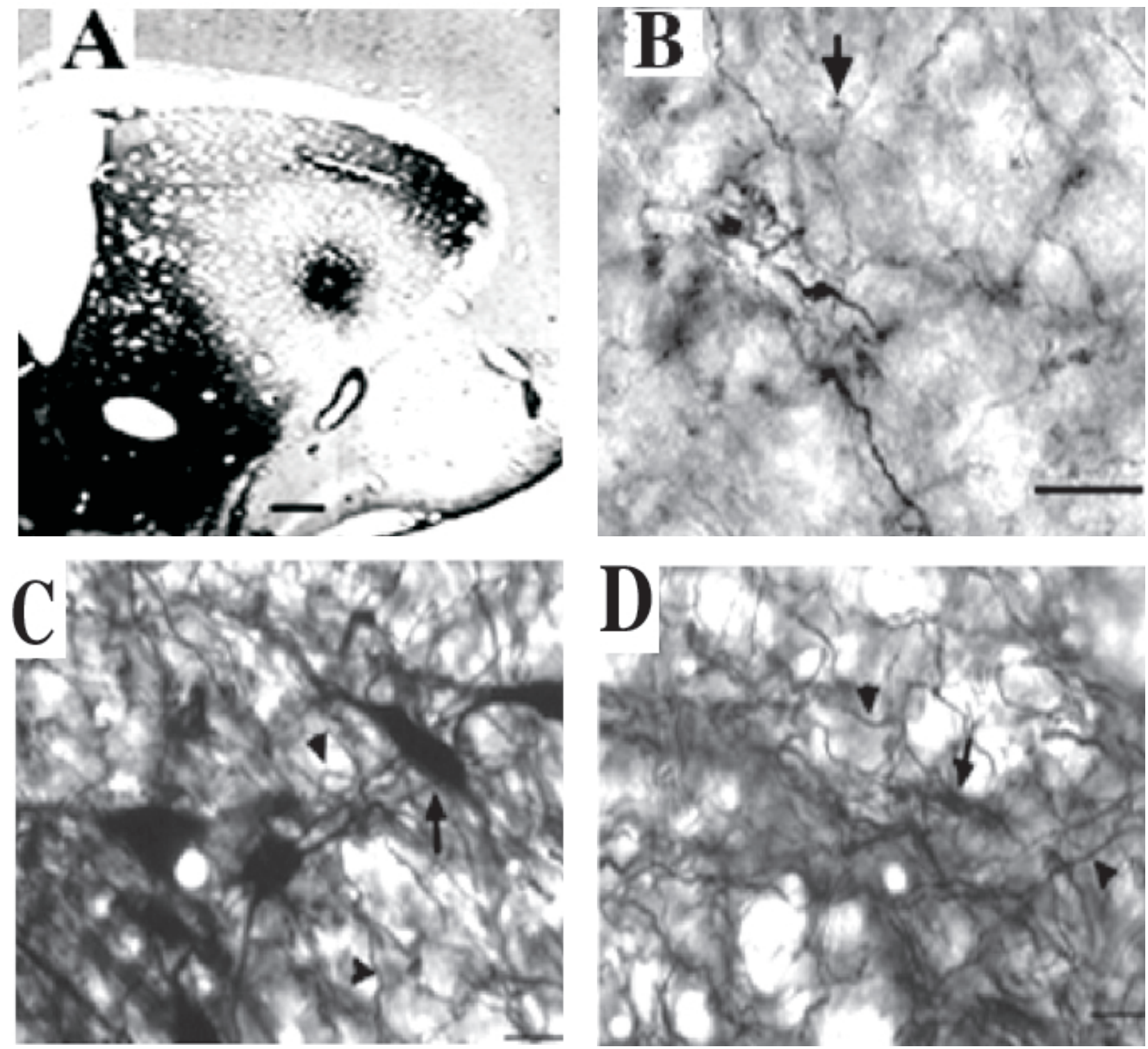

FIGURE 4 - Digital image showing tyrosine hydroxylase (TH) immunoreactivity in coronal sections of the neostriatum (A, B) and pars compacta of the substantia nigra $(C, D)$ of rats that have received a 6-hydroxydopamine injection $(A, B, D)$ or solvent $(C)$ in the left side of the neostriatum. The animals were killed 22 days after the injection. Figure B was depicted from the neostriatum close to the injection site of the animal showed in A. The remaining TH immunoreactive fibers and varicosities (arrow) are seen. An intense disappearance of TH immunoreactive varcosities is seen close to the injection site (A, B). TH immunoreactive neuronal cell bodies (arrows) and processes (arrowheads) are pointed (C, D). A disappearance of dopamine cell bodies is seen in the ipsilateral pars compacta of the substantia nigra after striatal injection of the neurotoxin (D). Bars=100?m (A), 50?m (B, C, D).

The stereological analysis demonstrated a $32 \%$ reduction in the number of $\mathrm{TH}$ immunoreactive varicosities in the ipsilateral neostriatum of the 6-OHDA injected rats (Figure 5A). There was a decrease of 54\% in the number of $\mathrm{TH}$ immunoreactive neurons in the ipsilateral SNc of the 6-OHDA lesioned rats (Figure
$5 \mathrm{~B})$. No changes in the number of $\mathrm{TH}$ immunoreactive varicosity and of the $\mathrm{TH}$ immunoreactive neurons were found in the sampled contralateral neostriatum and $\mathrm{SNc}$, respectively, of the 6-OHDA striatal injected rats 22 days after surgery (Figure 5). 


\section{Tyrosine Hydroxylase Estimated Number}

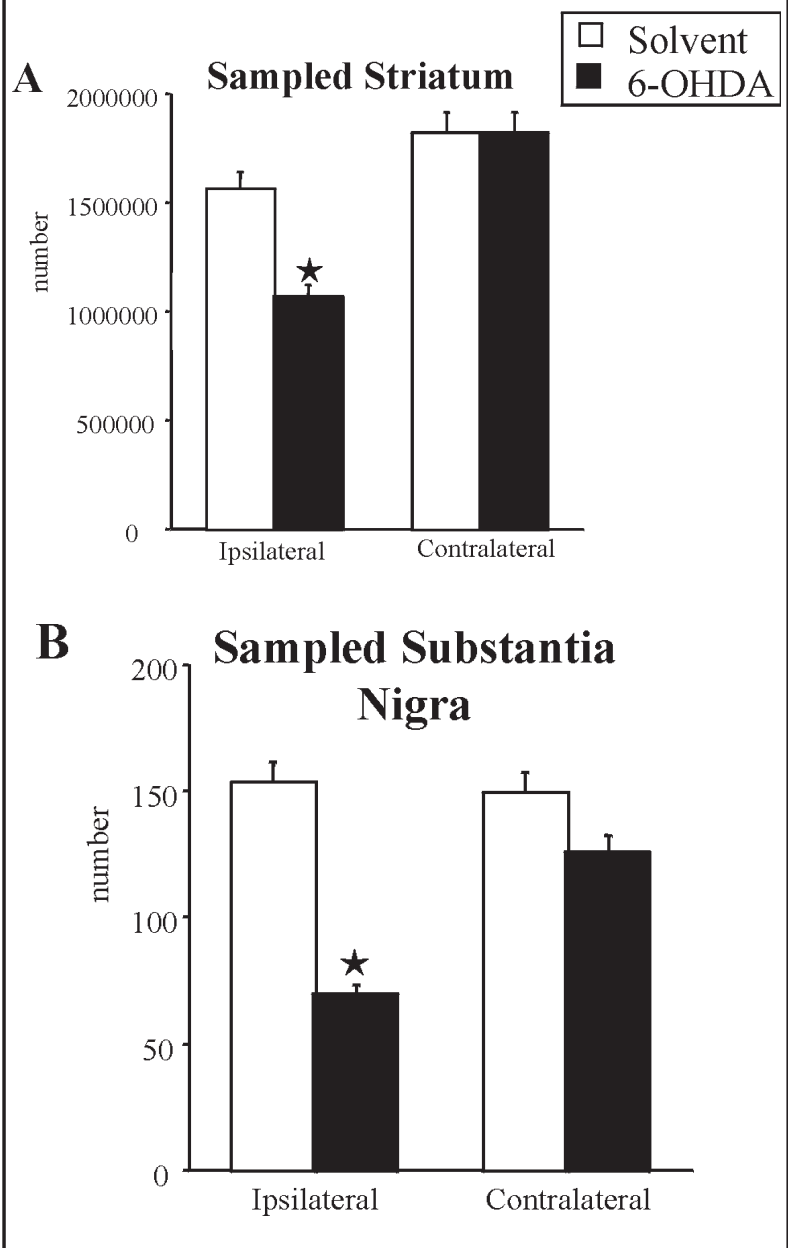

FIGURE 5 - Effects of the unilateral striatal injection of 6hydroxydopamine in a dose of $8 \mathrm{mg} / 4 \mathrm{ml}(\mathrm{n})$ or solvent $(\mathrm{O})$ on the number of TH immunoreactive varicosity (A) and cell body profiles (B) in the sampled fields placed in the neostriatum (A) and pars compacta of the substantia nigra (B) in the ipsilateral and contralateral sides of injection. Stereological method employing the optical disector was used. Means \pm s.e.m. $n=4-3$. The statistical analysis was performed using non-parametric Mann Whitney $U$-test. Hp $<0.05$.

GFAP immunoreactivity: The GFAP immunohistochemistry revealed an increased density of the astroglial GFAP immunoreactive profiles in the ipsilateral neostriatum and SNc of the 6-OHDA lesioned rats (illustrated in the figure 6B). The reactive astrocytes possessed increased size of the cytoplasm and number of processes (Figure 6B). An astrocytic reaction was found in the neostriatum of the solvent injected rats only bordering the needle track (not shown). The GFAP immunoreactivity was not changed within the SNc of the solvent treated rats.

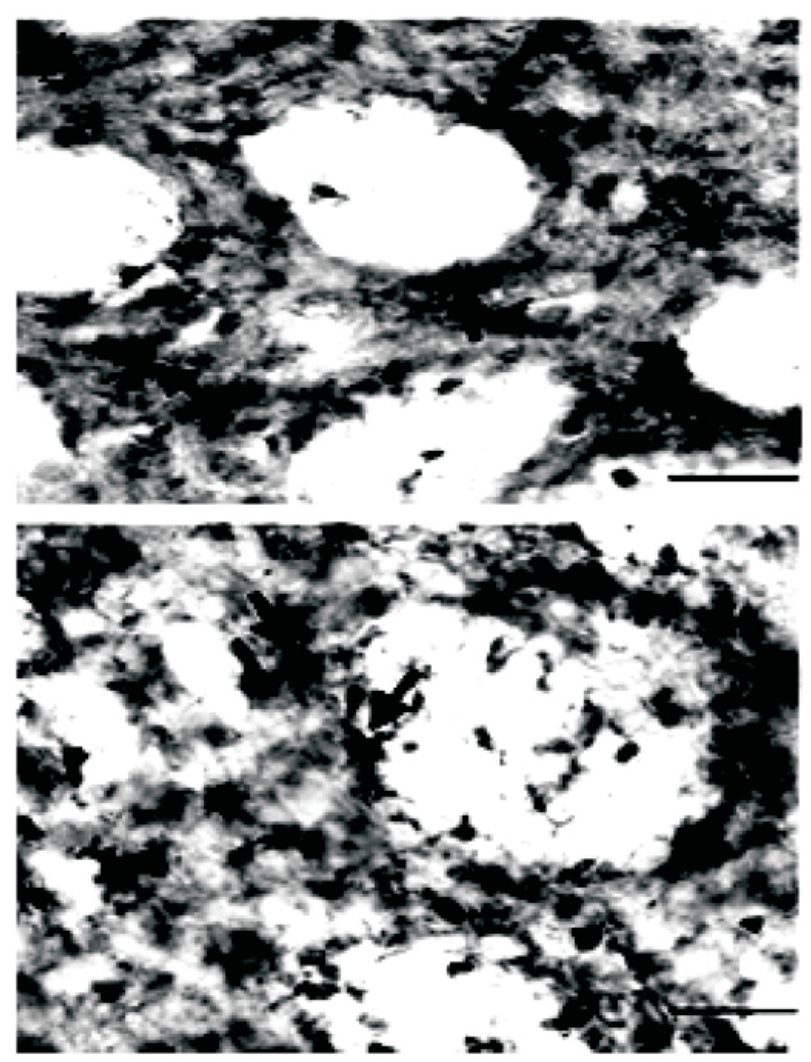

FIGURE 6 - Digital image of glial fibrillary acidic protein (GFAP) immunoreactivity in coronal section of the neostriatum of rats that received a solvent (A) or a 6-hydroxydopamine injection (B) in the left side of the neostriatum. The animals were killed 22 days after the injection. Astroglial GFAP immunoreactive profiles are pointed (arrow). Striatal injection of 6-hydroxydopamine leads to an astroglial reaction in the neostriatum which is represented by an increased number of larger astrocytes (B). Bars $=50 \circ \mathrm{m}$.

The stereological analysis demonstrated a significant increased number of GFAP immunoreactive astroglial cells in the ipsilateral neostriatum (137\%) and ipsilateral SNc $(83 \%)$ of the 6-OHDA injected rats (Figure 7). The number of astroglial immunoreactive profiles did not change in the contralateral neostriatum and SNc after striatal 6-OHDA injection (Figure 7). 


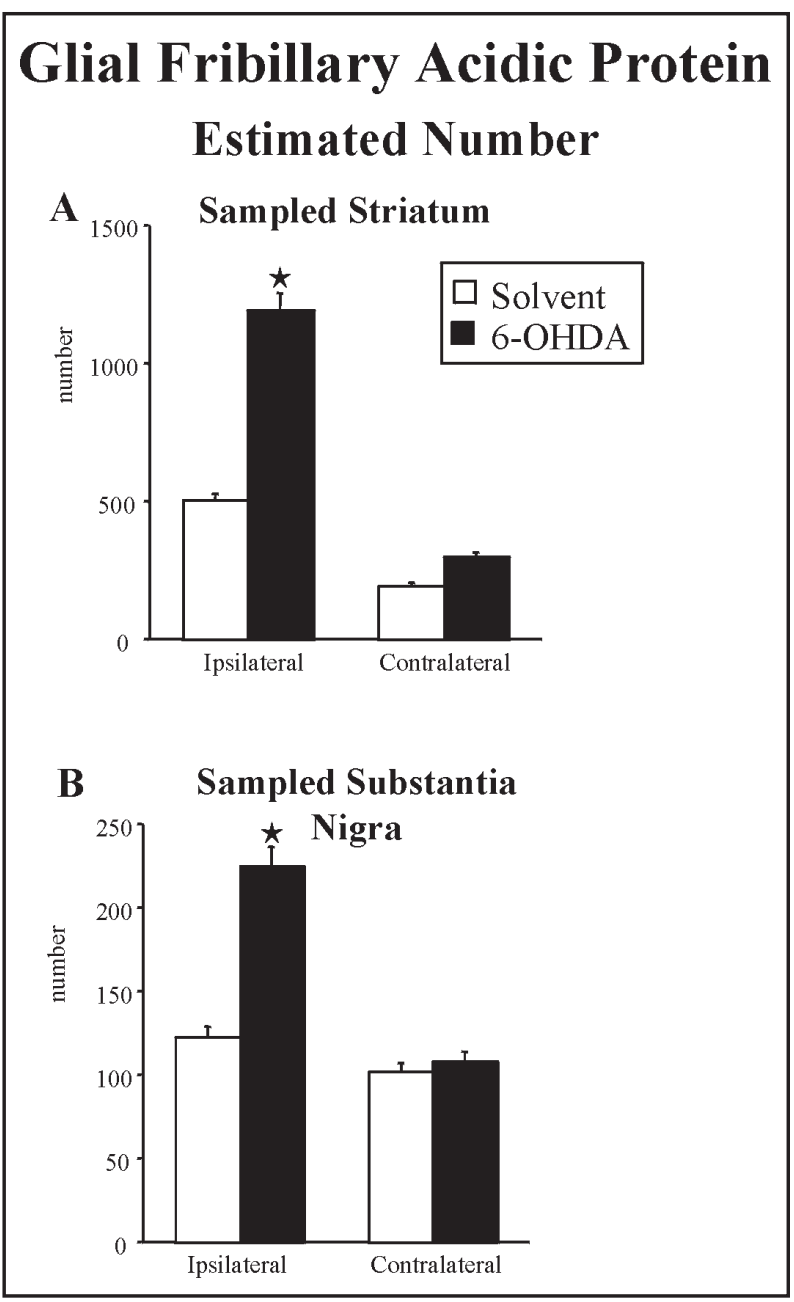

FIGURE 7 - Effects of the unilateral striatal injection of 6hydroxydopamine in a dose of $8 \mathrm{mg} / 4 \mathrm{ml}(\mathrm{n})$ or solvent (o ) on the number of glial fibrillary acidic protein (GFAP) immunoreactive profiles in the sampled fields placed in the neostriatum (A) and pars compacta of the substantia nigra (B) in the ipsilateral and contralateral sides of injection. Stereological method employing the optical disector was used. Means \pm s.e.m. $n=4-3$. The statistical analysis was performed using nonparametric Mann Whitney $U$-test. Hp $<0.05$.

OX42 immunoreactivity: The OX42 immunohistochemistry showed an increased number of microglial OX42 immunoreactive cells in the ipsilateral neostriatum and SNc of 6-OHDA injected rats (illustrated in the Figure 8). In the solvent control group the OX42 immunoreactivity was not changed in the ipsilateral neostriatum of the solvent injected rats as well as in the contralateral neostriatum of the rats of both 6-OHDA and solvent groups (not shown).
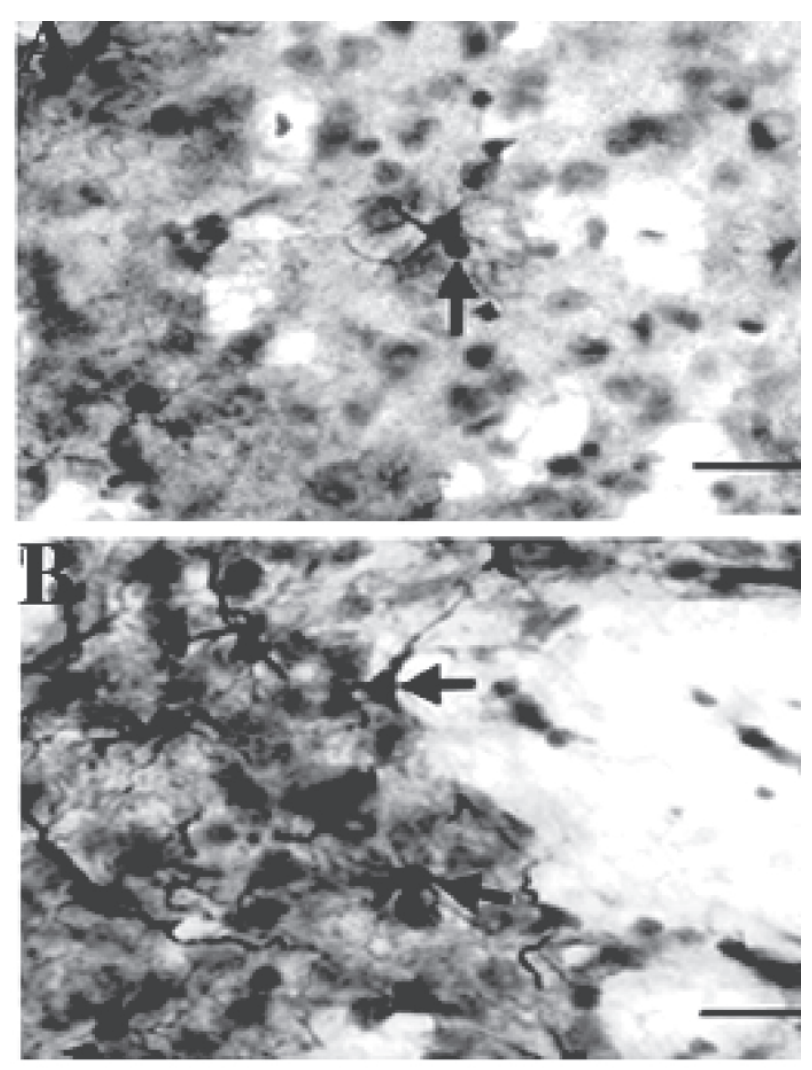

FIGURE 8 - Digital image of OX42 immunoreactivity in coronal section of the neostriatum of rats that received a solvent (A) or a 6-hydroxydopamine injection (B) in the left side of the neostriatum. The animals were killed 22 days after the injection. Microglial OX42 immunoreactive profiles are pointed. Striatal injection of 6-hydroxydopamine leads to a microglial reaction in the neostriatum which is represented by an increased number of larger microglial cells (B). Bars $=50$ ?m.

The stereological analysis revealed increases of $67 \%$ and $100 \%$ in the number of microglial OX42 immunoreactive cells in the ipsilateral neostriatum and $\mathrm{SNc}$, respectively, of the 6-OHDA lesioned rats (Figure 9). The counts demonstrated no changes in the number of microglial immunoreactive profiles in the contralateral neostriatum and SNc after 6-OHDA injection (Figure 9). 


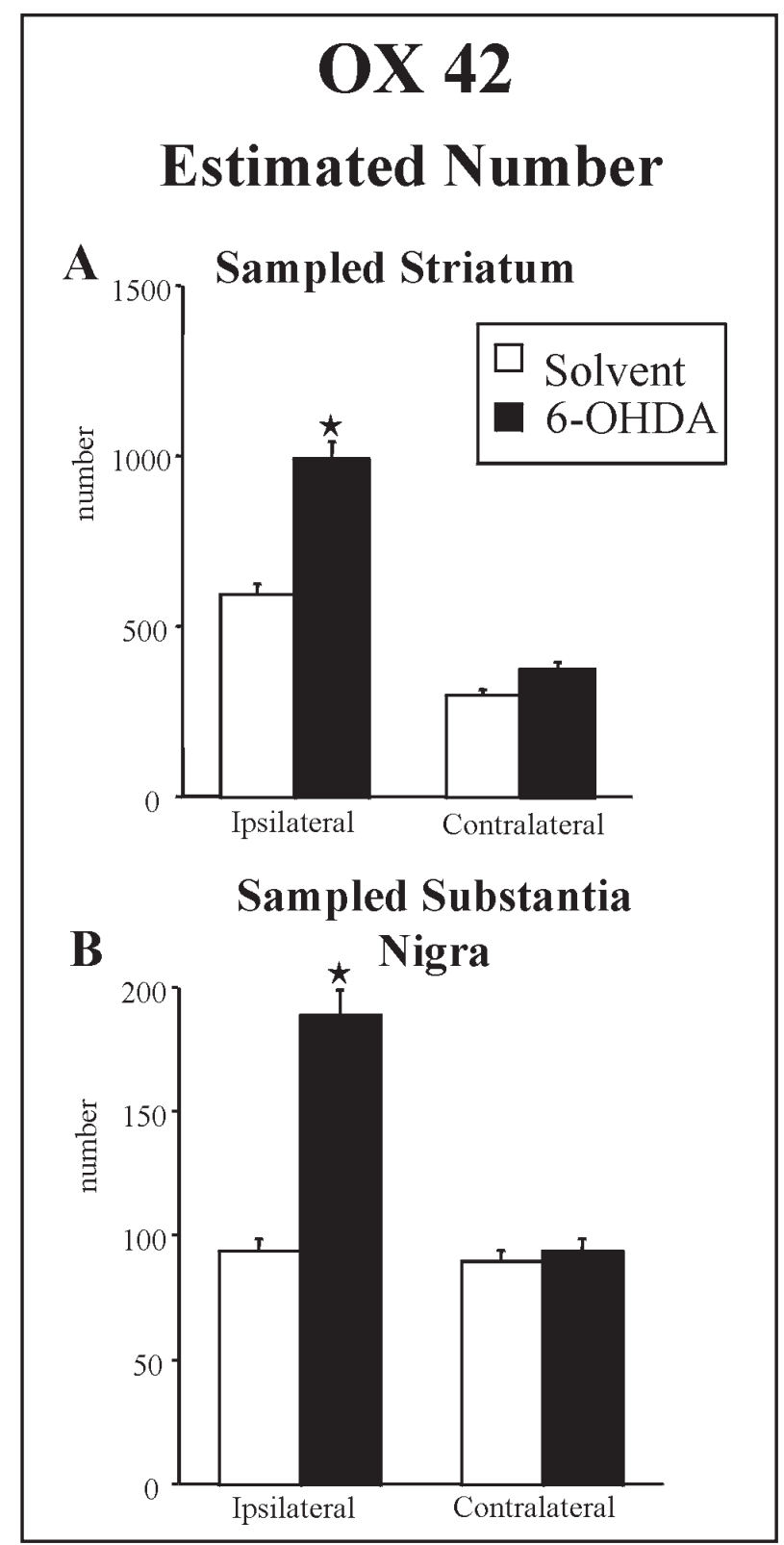

FIGURE 9 - Effects of the unilateral striatal injection of 6hydroxydopamine in a dose of $8 \mathrm{mg} / 4 \mathrm{ml}(\mathrm{n}$ ) or solvent (o ) on the number of OX42 immunoreactive profiles in the sampled fields placed in the neostriatum (A) and pars compacta of the substantia nigra (B) in the ipsilateral and contralateral sides of injection. Stereological method employing the optical disector was used. Means \pm s.e.m. $n=4-3$. The statistical analysis was performed using non-parametric Mann Whitney $U$-test. H $\mathrm{p}<0.05$.

\section{Discussion}

6-OHDA injection in the substantia nigra triggering a massive disappearance of dopamine neurons in the ipsilateral nigrostriatal pathway and apomorphineinduced contralateral rotation ${ }^{23,14}$ is classical model to promote experimental parkinsonism in rats. Recently,
6-OHDA-induced lesion in the nigrostriatal dopamine pathway has been achieved after striatal injection of 6OHDA $^{23,24}$.

The present paper demonstrated the effects of 6OHDA striatal injection on the degeneration of the nigrostriatal TH immunoreactivity as well as on the degree of apomorphine-induced stereotyped rotational behavioral in rats. The subsequent astroglial and microglial activation following dopamine lesion was also analysed.

Stereotyped rotational behaviour is triggered in 6OHDA lesioned rats after the apomorphine administration. The circling behaviour is archieved when the striatal post-synaptic dopamine receptors become supersensitive after dopamine lesion ${ }^{25,26}$. The present paper showed increases in the mean of contralateral turns in lesioned rats 22 days after 6-OHDA striatal injection. Reductions of the number of TH positive varicosities in the neostriatum and dopamine neurons in the SNc in the ipsilateral side of the 6-OHDA injection were also described in this paper. These findings are in agreement with previous reports which demonstrated decreases in the dopamine levels within the neostriatum after a local injection of 6-OHDA ${ }^{27,23}$ and a disappearance of TH immunoreactive cell bodies within the ipsilateral side of $\mathrm{SNc}^{24}$. Furthermore, Cadet and co-workers ${ }^{28}$ have shown a diminution of $\mathrm{TH}$ immunoreactivity in the neostriatum and in the $\mathrm{SNc}$ after a striatal injection of 6-OHDA ${ }^{28}$.

Taken together, the results of previous papers and the findings of this work indicate the occurence of a retrograde degeneration of the dopamine nigrostriatal system following a striatal injection of 6-OHDA in rats. Furthermore, the degree of the dopamine lesion can be measured behaviorally and using stereological method combined with TH immunoreactivity.

Several papers have demonstrated astroglial reaction after a brain lesion ${ }^{29,30,5}$. Astroglial activation has been observed close to the lesion site ${ }^{3}$ and also accompaining the lesioned neuronal pathways ${ }^{2}$. Once activated, astroglial cells synthesize increased amount of GFAP and undergo morphological changes ${ }^{31}$.

The present report described intense astroglial reaction in the nigrostriatal dopamine system 22 days after an unilateral 6-OHDA striatal injection. These findings indicate that the astroglial activation occurs not exclusively close the lesion site of the 6-OHDA striatal injection where the astroglial reaction can be related to the scar and wound repair but also in the ipsilateral $\mathrm{SNc}$, accompaining the retrograde degeneration of the nigrostriatal projection. 
After a CNS lesion microglial cells trigger phagocytosis ${ }^{12}$ In that state microglia become ameboid, retract their processes and replicate. In the present work we have observed microglial activation close to the striatal site of 6-OHDA injection and also in the ipsilateral SNc. These data are similar to that found by Akiyama and co-workers ${ }^{32}$ that observed reactive microglia surrounding lesioned dopamine neurons ${ }^{32}$. Microglial activation in the lesioned neostriatum and in the ipsilateral SNc may be related to the elimination of neuronal debris.

It has to be emphasized that the degree of astroglial and microglial activation was very similar as it was the regions i.e. ipsilateral 6-OHDA lesioned nigrostriatal pathway where both glial cells underwent reaction.
These observations already indicate a possible modulation between these two glial cell populations ${ }^{7}$. The release of microglial interleukins has been mentioned to be involved in the activation of near astrocytes which in turn synthesize increased amounts of substances of neurotrophic properties ${ }^{7,8}$. Thus, the findings of the present paper are in line with previous reports that have shown that chemical modulation of reactive glial cells may regulate immunological response in the lesioned CNS, triggering neuronal survival or death ${ }^{12,33}$. The modulation of reactive microglia and astrocytes may have triggered trophic responses in the lesioned nigrostriatal pathway that may have interfered with the degree of dopamine lesion. These phenomena is summarized in the Figure 10.

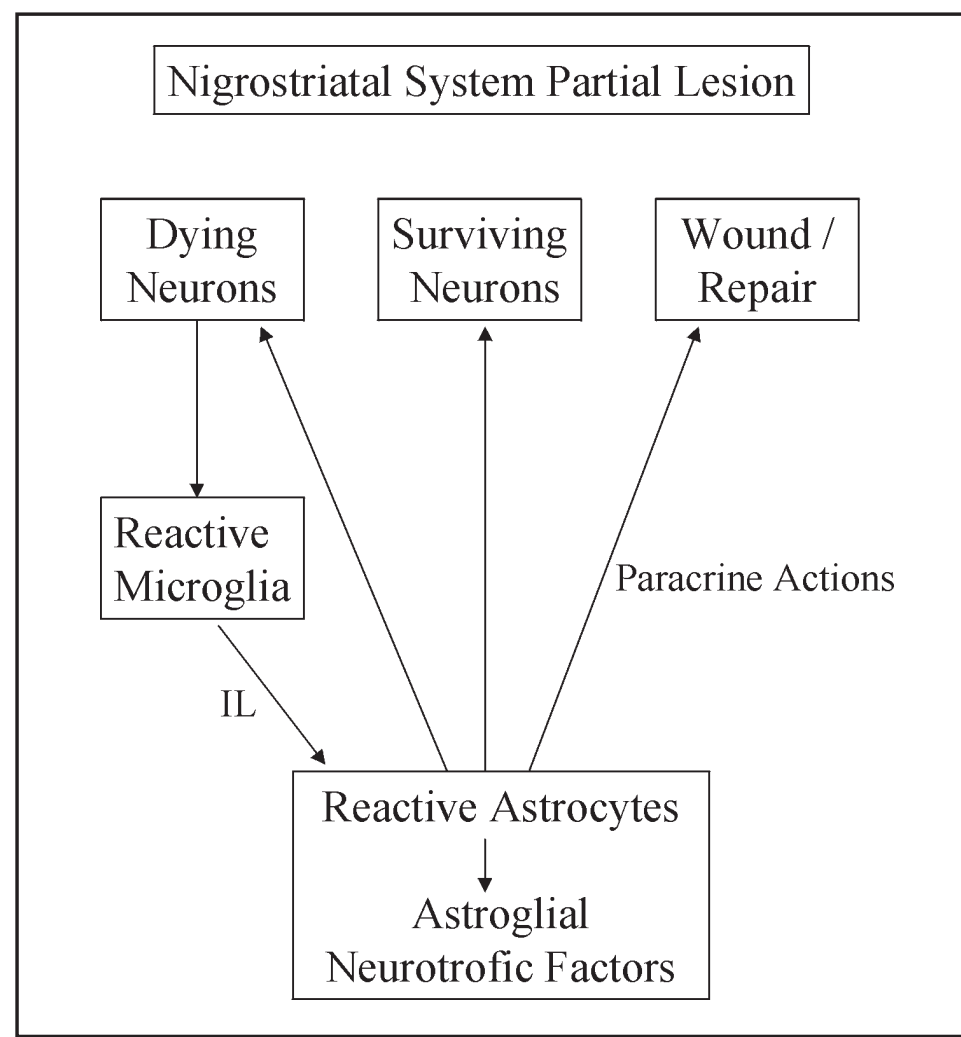

FIGURA 10 - Schematic illustration of the possible action of reactive astrocytes after a partial lesion of the dopamine nigrostriatal system promoted by a striatal injection of 6-hydroxydopamine. Injured dopamine neurons trigger the secretion of interleukins (IL) by activated microglia which stimulate astrocytes to become reactive. The synthesis of neurotrophic substances is then up-regulated in the reactive astrocytes which via paracrine actions may help maintain lesioned dopamine neurons as well as promote wound/repair.

\section{Conclusion}

In conclusion, striatal injection of 6-OHDA leads to the lesion of local dopamine terminals and retrograde degeneration of nigral dopamine neurons. The lesion of the nigrostriatal system is accompained by an astroglial and microglial reaction in the nigrostriatal pathway which may be related to the paracrine trophic actions on remaining dopamine neurons. 


\section{References}

1. Bignami A, Dahl D. The astroglial response to stabbing. Immunofluorescence studies with antibodies to astrocytespecific protein (GFA) in mammalian and submammalian vertebrates. Neuropathol Appl Neurobiol 1976;2: 99-111.

2. Cerutti S. M., Chadi G. S100 immunoreactivity is increased in reactive astrocytes of the visual pathways following a mechanical lesion of the rat occipital cortex. Cell Biol Int 2000;24: 35-49.

3. Gomide V. C., Chadi G. The trophic factors S-100beta and basic fibroblast growth factor are increased in the forebrain reactive astrocytes of adult callosotomized rat. Brain Res 1999;835: 162-74.

4. Shao Y, McCarthy KD. Plasticity of astrocytes. Glia 1994;11: 147-55.

5. Goss JR, Morgan DG. Enhanced glial fibrillary acidic protein RNA response to fornix transection in aged mice. $\mathrm{J}$ Neurochem 1995;64: 1351-60.

6. Streit WJ, Graeber MB Kreutzberg GW. Functional plasticity of microglia: a review. Glia 1988;1: 301-7.

7. Giulian D, Vaca K, Corpuz M. Brain glia release factors with opposing actions upon neuronal survival. J Neurosci 1993;13: 29-37.

8. Chadi G, Cao Y, Pettersson RF, Fuxe K. Temporal and spatial increase of astroglial basic fibroblast growth factor synthesis after 6-hydroxydopamine-induced degeneration of the nigrostriatal dopamine neurons. Neuroscience 1994;61: 891910 .

9. Frautschy SA, Walicke PA, Baird A. Localization of basic fibroblast growth factor and its mRNA after CNS injury. Brain Res 1991;553: 291-9.

10. Fawcett J. Astrocytes and axon regeneration in the central nervous system. J Neurol 1994;242: S25-8.

11. Chadi G, Rosen L, Cintra A, Tinner B, Zoli M., Pettersson RF, Fuxe K. Corticosterone increases FGF-2 (bFGF) immunoreactivity in the substantia nigra of the rat. Neuroreport 1993a;4: 783-6.

12. Giulian D. Ameboid microglia as effectors of inflammation in the central nervous system. J Neurosci Res 1987;18: 155-71, 132-3.

13. Hetier E, Ayala J, Denefle P, Bousseau A, Rouget P, Mallat M, Prochiantz A. Brain macrophages synthesize interleukin-1 and interleukin-1 mRNAs in vitro. J Neurosci Res 1988;21: 391-7.

14. Ungerstedt U. Postsynaptic supersensitivity after 6-hydroxydopamine induced degeneration of the nigro-striatal dopamine system. Acta Physiol Scand Suppl 1971;367: 69-93.

15. Ungerstedt $\mathrm{U}$, Arbuthnott GW. Quantitative recording of rotational behavior in rats after 6-hydroxy-dopamine lesions of the nigrostriatal dopamine system. Brain Res 1970;24: 485-93.

16. Paxinos $\mathrm{G}$, Watson $\mathrm{C}$. The rat brain: in stereotaxic coordinates. 1986.

17. Zamboni I, DeMartino C. Buffered picric acid formaldehyde: a new rapid fixative for electron microscopy. J Cell Biol 1967;35: 148A.

18. Hsu SM, Raine L, Fanger H. Use of avidin-biotin-peroxidase complex $(\mathrm{ABC})$ in immunoperoxidase techniques: a comparison between $\mathrm{ABC}$ and unlabeled antibody (PAP) procedures. J Histochem Cytochem 1981;29: 577-80.

19. Zoli M, Zini I, Agnati LF, Guidolin D, Ferraguti F, Fuxe K. Aspects of neuronal plasticity in the central nervous system.
I.Computer-assisted image analysis methods. Neurochem Int 1990;16: 383-418.

20. Janson AM., Moller A. Chronic nicotine treatment counteracts nigral cell loss induced by a partial mesodiencephalic hemitransection: an analysis of the total number and mean volume of neurons and glia in substantia nigra of the male rat. Neuroscience 1993;57: 931-41.

21. Chadi G, Moller A, Rosen L, Janson AM, Agnati LA, Goldstein M, Ogren SO, Pettersson R, Fuxe K. Protective actions of human recombinant basic fibroblast growth factor on MPTPlesioned nigrostriatal dopamine neurons after intraventricular infusion. Exp Brain Res 1993b;97: 145-58.

22. Hollander M, Wolfe DA. Non-parametric statistical methods. 1973.

23. Przedborski S, Levivier M, Jiang H, Ferreira M, Jackson-Lewis V, Donaldson D, Togasaki DM. Dose-dependent lesions of the dopaminergic nigrostriatal pathway induced by intrastriatal injection of 6-hydroxydopamine. Neuroscience 1995;67: 63147.

24. Kirik D, Rosenblad C, Bjorklund A. Characterization of behavioral and neurodegenerative changes following partial lesions of the nigrostriatal dopamine system induced by intrastriatal 6-hydroxydopamine in the rat. Exp Neurol 1998;152: 259-77.

25. Schwarting RK, Huston JP. The unilateral 6-hydroxydopamine lesion model in behavioral brain research. Analysis of functional deficits, recovery and treatments. Prog Neurobiol 1996;50: 275-331.

26. Hefti F, Melamed E, Wurtman RJ. Partial lesions of the dopaminergic nigrostriatal system in rat brain: biochemical characterization. Brain Res 1980;195: 123-37.

27. Lee CS, Sauer H, Bjorklund A. Dopaminergic neuronal degeneration and motor impairments following axon terminal lesion by instrastriatal 6-hydroxydopamine in the rat. Neuroscience 1996;72: 641-53.

28. Cadet JL, Last R, Kostic V, Przedborski S, Jackson-Lewis V. Long-term behavioral and biochemical effects of 6hydroxydopamine injections in rat caudate-putamen. Brain Res Bull 1991;26: 707-13.

29. Baumann N, Baron-Van Evercooren A, Jacque C, Zalc B. Glial biology and disorders. Curr Opin Neurol Neurosurg 1993;6: 27-33.

30. Niquet J, Ben-Ari Y, Represa A. Glial reaction after seizure induced hippocampal lesion: immunohistochemical characterization of proliferating glial cells. J Neurocytol 1994;23: 641-56.

31. Stromberg I, Bjorklund H, Dahl D, Jonsson G, Sundstrom E, Olson L. Astrocyte responses to dopaminergic denervations by 6-hydroxydopamine and 1-methyl-4-phenyl-1,2,3,6tetrahydropyridine as evidenced by glial fibrillary acidic protein immunohistochemistry. Brain Res Bull 1986;17: 225-36.

32. Akiyama H, McGeer PL. Microglial response to 6hydroxydopamine-induced substantia nigra lesions. Brain Res 1989;489: 247-53.

33. Giulian D, Li J, Leara B, Keenen C. Phagocytic microglia release cytokines and cytotoxins that regulate the survival of astrocytes and neurons in culture. Neurochem Int 1994;25: 227-33.

\section{Acknowledgements}

We wish to thank Ms. Patrícia R. de Campos for excellent technical assistance. 
Rodrigues RWP, Gomide VC, Chadi G. Striatal Injeção estriatal de 6-hidroxidopamina induz degeneração retrógrada e ativação glial na via nigro-estriatal. Acta Cir Bras [serial online] 2003 JulAgo;18(4). Disponível em URL: http://www.scielo.br/acb.

RESUMO - Objetivo: O efeito de uma lesão altamente seletiva induzida pela 6-hidroxidopamina (6-OHDA) no sistema nigroestriatal dopaminérgico sobre a ativação astroglial e microglial foi analisado em ratos Wistar adultos após uma injeção unilateral da neurotoxina no estriado. Métodos: Ratos receberam injeção estereotáxica unilateral de 6-OHDA no lado esquerdo do neoestriado e foram sacrificados 22 dias depois. Os animais controles receberam injeção de solvente. O comportamento rotacional foi registrado antes do sacrifício. A técnica da imunohistoquímica foi utilizada para a visualização das células dopaminérgicas positivas à tirosina hidroxilase $(\mathrm{TH})$, dos astrócitos marcados pela proteína glial fibrilar ácida (GFAP) e da microglia imunorreativa ao OX42. O método estereológico empregando o dissector óptico foi usado para estimar o grau das mudanças no sistema nigroestriatal. Resultados: A injeção estriatal de 6-OHDA induziu o desaparecimento massivo (32\% do controle) de terminais imunorreativos à TH numa área definida dentro do estriado, ao redor do local da injeção. Desaparecimento de corpos celulares dopaminérgicos (54\% do controle) foi observado em pequena região da porção compacta da substância negra $(\mathrm{SNc})$ ipsilateral. A imunohistoquímica da GFAP e da OX42 revelou reação astroglial e microglial (aumentos no número e tamanho das células) no estriado ipsilateral e na SNc ipsilateral de ratos injetados com a 6-OHDA. Conclusões: A injeção estriatal de 6-OHDA leva à degeneração retrógrada, bem como à ativação astroglial e microglial na via nigroestriatal dopaminérgica. A modulação das células gliais ativadas pode estar relacionada à cicatrização e à resposta trófica parácrina no sistema nigroestriatal lesado.

DESCRITORES - Astrócito. Microglia. Imunohistoquímica. Lesão dopaminérgica. Ativação glial.

Conflict of interest: none

Financial sources: FAPESP and CNPq

Correspondence:

Gerson Chadi

Department of Anatomy. ICB. USP

Av Prof Lineu Prestes, 2415

05508-900 São Paulo - SP Brazil

Phone: (11)3091-7384

Fax: (11)3091-7366

gerchadi@usp.br

Data do recebimento: 28/03/2003

Data da revisão: $13 / 04 / 2003$

Data da aprovação: 24/04/2003 